\title{
Editorial
}

\section{WASTE BIOREFINERIES: OPPORTUNITIES AND PERSPECTIVES}

Biorefinery concepts and technologies have developed rapidly and intensively for a series of reasons:

- Progressive implementation of the circular economy concepts;

- Population growth and associated concerns over availability of non-renewable resources, differentiation of strategic sources for materials and energy supplies;

- Avoidance of relying on sources located in politically and socially unstable areas;

- Need to control global climate changes;

- Delocalization of production systems;

- Promotion of regional and rural development.

An increasing knowledge of the factors governing biological processes has rendered biowaste management more ambitious, with processes aimed at achieving more articulated targets. The inherent potential of biorefineries is huge. The global industrial production of organic chemicals accounts for a major share of the overall global chemicals industry, being estimated to amount, excluding fuels, to more than $300 \mathrm{Mt} /$ year; the associated market was worth over 6 billion \$ in 2014 and grew at an average of 8\% per year from 2009 to 2014. Primary outputs of the chemical industry are represented by a relatively limited number of building blocks used to produce a plethora of end-products destined for use in food and beverages, pharmaceuticals, pesticides, agrochemicals, water treatment, crop protection, personal care products and cosmetics, fertilizers, the automotive industry, gasoline additives, polymers and chemicals, etc. Each building block may however also be obtained from biomass, enabling the supply of raw materials at a local level, thus relieving the industrial sector from relying on expensive and risky supplies, and opening the door to economic sustainability even in disadvantaged contexts such as insular settings. Depending on market conditions, the demand for bioproducts from renewable sources is estimated to reach 26-113 Mt/year in 2050, corresponding to 38 and $17 \%$ of the total organic production of chemicals, respectively; the associated market should account for some 7-8 billion \$, with a growth rate of 15\%/year which could further benefit from the increasing demand for biopolymers (IEA Bioenergy - Task 42 Biorefinery, 2012).

A biorefinery is not a completely new concept, but has rather evolved over time driven by three pivotal aspects:

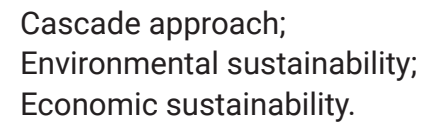

The cascade approach involves the flexible integration of a series of processes aimed at producing a mix of biofuels and bioproducts. The integration of processes and products according to the traditional or inverse cascade model is basically linked to economic sustainability, entailing an appropriate mix of products characterized either by significant market size - typical of biofuels - or high added value, but also to environmental aspects. Indeed, as the number of usable and marketable outputs increases, this would logically correspond to less waste production, thus approaching the zero-waste concept.

The improvement in environmental sustainability is also the main element underlying the hypothesis of transition towards a new generation of biorefineries: waste biorefineries. The environmental sustainability of the first and current biorefinery generations was, and still is, linked mainly to benefits related to reduction of the consumption of non-renewable resources and $\mathrm{CO}_{2}$ emissions. In this respect, it is estimated that the production of a large share of synthetic organic compounds from renewable resources could lead to a global reduction of $\mathrm{CO}_{2}$ emissions ranging between 400 and $1000 \mathrm{Mt} /$ year.

The use of residual biomass would promote additional environmental and economic benefits:

- An environmentally sound management of residues achieved by means of valorization;

- Providing a solution to the food-energy dilemma, resulting in crops not being processed for the production of biofuels or biochemicals, and farmland not being diverted from food production;

- A reduction in production costs, as waste biomass is a widely available and inexpensive feedstock, thus boosting the economy from the input yielded by waste treatment fees;

- The different environmental and economic dynamics that characterize waste biorefineries could contribute towards promoting the use of simpler and smaller plants for sustainable process schemes as compared to traditional biorefineries.

However, despite the potential advantages highlighted above, it is not conceivable that all technological and economic perspectives associated to traditional biorefineries could be fully extended to waste biorefineries, due to the nature of the residual biomass, which would be, arguably, qualitatively more heterogeneous and quantitatively less controllable.

Therefore, the following challenge awaits environmen-
Detritus / Volume 05 - 2019 / pages 1-2

https://doi.org/10.31025/2611-4135/2019.13791

(c) 2019 Cisa Publisher. Open access article under CC BY-NC-ND license 
tal researchers and technicians: is the biorefinery concept feasible for waste management? and to what extent?

A univocal answer can likely not be provided.

In contexts characterized by the availability of large traditional biorefineries, the search for synergies has resulted in waste biomass being considered as a secondary inflow that contributes mainly to the recovery of products characterized by a lower added value (energy, energy carriers, biofuels).

Conversely, where the main biomass to be treated is represented by organic waste, the question is whether and under what circumstances (availability and type of residues, market conditions, etc.) process schemes are applicable which, although lacking the complexity and articulation of treatment steps/final products achievable in a traditional biorefinery, move away from current relatively simple valorization options, such as the recovery of biogas/biomethane and composting, to approach the concept of industrial biorefinery.

Indeed, although some types of organic waste contain appreciable quantities of high value substances - or are suitable for conversion into valuable building blocks - thus worth exploiting in relatively small dedicated plants where extraction of compounds and energy recovery from the resulting residues are performed - the minimum size deemed sustainable from an economic point of view, the qualitative/quantitative characteristics of the waste biomass to be treated, the applicable processes, and the recoverable products, remain subjects of debate.

Traditional biorefineries frequently dictate the use of large plants; it is well acknowledged that the minimum size to ensure economic sustainability is about $500,000-700,000$ $t /$ year (Kuchta, 2016). The use of waste biomass may lead to a lowering of this threshold, provided that the benefits in terms of simpler process schemes and revenues from waste treatment fees exceed the drawbacks related to the anticipated lower quality of final outputs and less ambitious market targets. However, under most circumstances, the less stringent requirements in terms of minimum plant size would not allow for a process based on the treatment of a single type of residue. Currently therefore, waste biorefineries should probably co-treat different types of residues, either of municipal origin or deriving from production activities, with all the advantages and problems associated with co-treatment, as highlighted by the experience gained with anaerobic digestion.

As for the processes to be applied, the pivotal role that fermentation would play in a waste biorefinery scheme, due to its ability to hydrolyze and simplify the organic substance and convert it to marketable products or building blocks, should be emphasized. Indeed, the number of building blocks attainable through fermentation is remarkable, with the current global production of fermentation products amounting to more than $8 \mathrm{Mt} /$ year with an associated market exceeding 20 billion \$ (IEA Bioenergy - Task 42 Biorefinery, 2012). However, fermentation is a complex process, particularly when applied to heterogenous sub- strates containing indigenous microorganisms, and strongly depends on numerous interconnected factors such as substrate chemical composition, concentration and pretreatment methods, presence/type of inoculum and eventual pretreatment, inoculum to substrate ratio, reactor type and operation regime, applied operating conditions (e.g., $\mathrm{pH}$, hydraulic and cell residence time, temperature, organic loading rate, etc.) (Alibardi and Cossu, 2015; De Gioannis et al., 2013). Therefore, a better understanding of the complex interrelations between the relevant factors and, in turn, predicting the evolution of the process and optimizing performance when applied to residual biomass, is crucial.

With regard to potential products, on examining the current conditions in several European countries, featuring strong incentives for the production of biomethane, a possible simplified and readily applicable waste biorefinery scheme could consist of an anaerobic process performed in two stages, with the first properly managed to recover $\mathrm{H}_{2}+\mathrm{CO}_{2}$ from fermentation, in addition to the $\mathrm{CH}_{4}+\mathrm{CO}_{2}$ mixture to be produced in the second stage. Both mixtures should be refined to recover biohydrogen and biomethane, which could be then used individually or as a mixture (hythane). The separated $\mathrm{CO}_{2}$ could be reused or marketed or, alternatively, should use of $\mathrm{H}_{2}$ not yet be well established, both fed to reactors in which carbon dioxide is biologically reduced, with the aim of increasing overall biomethane production. Possible alternatives could include commercialization of the organic acid-rich solution produced in the fermentative hydrogenogenic stage, or innovative valorization of the same as a readily biodegradable substrate for biopolymer production or feedstock for bioelectrochemical systems (BES) underlying production of electrical energy (microbial fuel cells - MFC), biohydrogen or hydrogen peroxide or caustic solutions (microbial electrolysis cells MEC), or even synthesis of organic compounds (microbial electrosynthesis - MES).

Aldo Muntoni

Department of Civil and Environmental Engineering and Architecture, University of Cagliari, Piazza d'Armi, 09123 Cagliari, Italy

amuntoni@unica.it

\section{REFERENCES}

Alibardi, L., Cossu, R., 2015. Composition variability of the organic fraction of municipal solid waste and effects on hydrogen and methane production potentials. Waste Manag. 36, 147-155 https://doi. org/10.1016/j.wasman.2014.11.019.

De Gioannis, G., Muntoni, A., Polettini, A., Pomi, R., 2013. A review of dark fermentative hydrogen production from biodegradable municipal waste fractions. Waste Manage. 33, 1345-1361, https://doi. org/10.1016/j.wasman.2013.02.019.

IEA Bioenergy - Task 42 Biorefinery, 2012. Innovating for Sustainable Growth: A Bioeconomy for Europe. Strategy for "innovating for sustainable growth: a bioeconomy for Europe".

Kuchta, K., 2016. Prospects and potentials of waste biorefineries. Lecture at "SIDISA 2016 - X International Symposium on Sanitary and Environmental Engineering, 19-23 June 2016, Rome, Italy. 